\title{
LETTER TO THE EDITOR RSV infection without ribavirin treatment in pediatric hematopoietic stem cell transplantation
}

Bone Marrow Transplantation (2016) 51, 1382-1384; doi:10.1038/ bmt.2016.124; published online 16 May 2016

Hematopoietic stem cell transplant (HSCT) patients infected with respiratory syncytial virus (RSV) have been reported as having complicated clinical courses and may progress from mild upper airway congestion to lower respiratory tract symptoms with increased morbidity such as airflow obstruction or death. ${ }^{1,2}$ No proven treatment exists for RSV infection in this setting. Some investigators have proposed inhaled ribavirin as a required primary therapy despite limited data, suggesting that its use with immunomodulators may halt clinical progression. ${ }^{3-7}$

We hypothesized that our transplant patients do not experience significant morbidity and mortality from RSV despite not receiving ribavirin therapy. Our cohort received testing of nasal secretions for common respiratory pathogens, including RSV, using a viral real-time PCR (RT-PCR) panel when they presented with respiratory symptoms. Similar methods (RT-PCR and culture) were used to identify coinfections. Patients were considered to have an upper respiratory tract infection (URTI) if they had RSV-positive RT-PCR from secretion analysis plus rhinorrhea, congestion, otitis media, pharyngitis and/or cough. Patients were considered to have a lower respiratory tract infection (LRTI) if they had RSV-positive RT-PCR from secretion analysis (nasopharyngeal swab or wash, endotracheal tube aspirate, bronchoalveolar lavage sampling) plus signs including hypoxia (new or increased oxygen requirement) and/or an infiltrate found on chest imaging. An RSV infection episode was defined in a patient who developed symptoms that fully resolved. In some instances, a single patient experienced more than one RSV infectious episode, resulting in more than one admission and/or medical intervention that resulted in resolution of symptoms.

Four hundred and fifty patients received allogeneic HSCT at our institution between June 2008 and December 2014 and 32 patients (7\%) had 37 RSV infectious episodes with a median age of 7.3 years at the time virus was first identified (Tables 1 and 2). There was no statistically significant difference in distribution of patients with or without RSV infection based on age, gender, diagnoses, transplant preparative regimen (myeloabloative versus reduced intensity conditioning; $\mathrm{TBI}$ versus non-TBI containing), stem cell donor source, specific GVHD prophylaxis medications, use of in vivo T-cell-depleting serotherapies, incidence of grade II-IV GVHD and neutrophil or platelet engraftment day post HSCT.

Thirty URTIs occurred in 26 patients, with four having more than one episode. Three of these four patients were already hospitalized at the time of the RSV infection. Eight (27\%) of 30 URTIs were diagnosed in patients with concurrent viruses: influenza A (1), influenza B (1), rhinovirus (4), adenovirus (1) or coronavirus (1). One patient with a single documented URTI episode was empirically treated with antibiotics for a communityacquired pneumonia despite no evidence of consolidation on chest X-ray. Imaging studies (chest X-rays and/or CT scans) were performed in 11 (37\%) URTIs and confirmed an absence of an LRTI. Twenty (67\%) of 30 URTls were diagnosed in patients already receiving scheduled IVIG supplementation every 1-2 weeks to prevent hypogammaglobulinemia. Five of these 20 infections
Table 1. Clinical characteristics, treatment and outcomes of patients with RSV infection

\begin{tabular}{|c|c|c|}
\hline Characteristic/outcome & \multicolumn{2}{|c|}{ Number } \\
\hline Number of patients with RSV infection & \multicolumn{2}{|c|}{32} \\
\hline Number of RSV episodes documented & \multicolumn{2}{|c|}{37} \\
\hline Age (years) at the time RSV was first identified & \multicolumn{2}{|c|}{$\begin{array}{l}\text { Median } 7.3 \\
\text { (range } 0.5-25.5)\end{array}$} \\
\hline Number of RSV URTI episodes & \multicolumn{2}{|c|}{$30 / 37(81 \%)$} \\
\hline Number of RSV LRTI episodes & \multicolumn{2}{|c|}{$7 / 37(19 \%)$} \\
\hline Number of patients with URTIs & \multicolumn{2}{|c|}{$26 / 32(81 \%)$} \\
\hline Number of patients with LRTIs & \multicolumn{2}{|c|}{$6 / 32(19 \%)$} \\
\hline $\begin{array}{l}\text { Number of RSV infectious episodes in } \\
\text { patients already admitted to the hospital }\end{array}$ & \multicolumn{2}{|c|}{$19 / 37(51 \%)$} \\
\hline $\begin{array}{l}\text { Number of days between admission and } \\
\text { identification of RSV }\end{array}$ & \multicolumn{2}{|c|}{$\begin{array}{l}\text { Median } 11.5 \\
\text { (range } 2-252 \text { ) }\end{array}$} \\
\hline $\begin{array}{l}\text { Number of RSV infectious episodes } \\
\text { requiring admission }\end{array}$ & \multicolumn{2}{|c|}{$11 / 37(30 \%)$} \\
\hline $\begin{array}{l}\text { Number of RSV infectious episodes } \\
\text { not requiring admission }\end{array}$ & \multicolumn{2}{|c|}{7 /37 (19\%) } \\
\hline $\begin{array}{l}\text { Duration (days) of hospitalization after } \\
\text { RSV was identified }\end{array}$ & \multirow{2}{*}{\multicolumn{2}{|c|}{$\begin{array}{c}\text { Median } 23 \\
\text { (range } 1-198) \\
\text { Median } 9 \\
\text { (range 1-239) }\end{array}$}} \\
\hline Duration (days) of RSV positivity & & \\
\hline & URTI & LRTI \\
\hline \multicolumn{3}{|l|}{ Treatment } \\
\hline IVIG alone & 19 & 6 \\
\hline IVIG+palivizumab & 4 & 1 \\
\hline None & 7 & 0 \\
\hline Progression from URTI to LRTI & \multicolumn{2}{|c|}{$2 / 7(29 \%)$} \\
\hline \multicolumn{3}{|l|}{ Radiology (chest X-ray/chest CT scan) } \\
\hline None performed & \multicolumn{2}{|c|}{ 20/37 (54\%) } \\
\hline Normal & \multicolumn{2}{|c|}{$15 / 37(41 \%)$} \\
\hline New infiltrate/parenchymal disease & \multicolumn{2}{|c|}{$2 / 37(5 \%)$} \\
\hline Oxygen requirement at diagnosis (LRTI) & \multicolumn{2}{|c|}{$5 / 7(71 \%)$} \\
\hline Oxygen requirement during course of RSV (LRTI) & \multicolumn{2}{|c|}{$6 / 7(86 \%)$} \\
\hline Ventilation (LRTI) & \multicolumn{2}{|c|}{$2 / 7(29 \%)$} \\
\hline Death directly related to RSV & \multicolumn{2}{|c|}{0} \\
\hline \multicolumn{3}{|l|}{ Deaths } \\
\hline GVHD & \multicolumn{2}{|l|}{1} \\
\hline Multisystem organ failure & \multicolumn{2}{|l|}{2} \\
\hline Coccidiomycosis & \multicolumn{2}{|l|}{1} \\
\hline Relapsed malignancy & \multicolumn{2}{|l|}{2} \\
\hline Bronchiolitis obliterans & \multicolumn{2}{|l|}{1} \\
\hline
\end{tabular}

were treated with an increase in frequency or additional doses of IVIG. Of the 10 URTIs in patients not receiving regularly scheduled IVIG, three received doses of IVIG as treatment after RSV was identified. Additionally, four patients received palivizumab. Twenty-one (70\%) URTIs were identified in patients receiving steroids or other immunosuppressive medications at the time of RSV identification. Four patients were receiving treatment for active acute GVHD. Five of 26 patients with URTI subsequently 


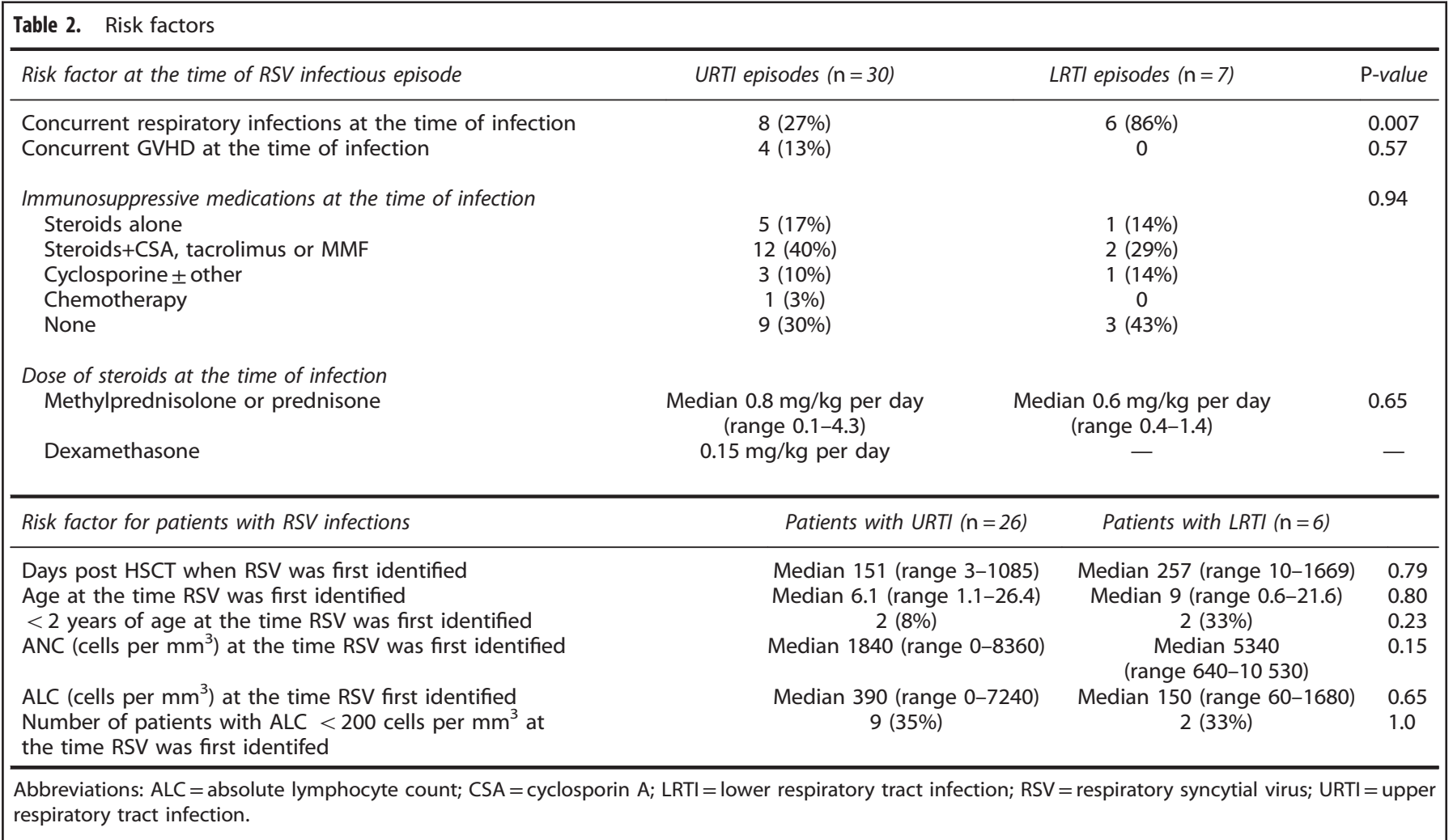

died, two patients from relapsed malignant disease and three from transplant-related complications. The latter three patients had documented clearance of RSV 42, 61 and 742 days before their deaths.

Four of seven LRTIs were diagnosed at a time when a patient was still receiving immunosuppression. No patient was receiving treatment for GVHD at the time RSV was identified. Three children were receiving steroids (alone or with other agents) when RSV was identified. Two of the six patients with LRTIs were $<2$ years at the time of RSV diagnosis, one with a significant history of prematurity. Two of six patients carried a diagnosis of bronchiolitis obliterans at the time their LRTIs were diagnosed. Six of seven LRTIs were associated with the identification of more than one respiratory tract organism besides RSV including metapneumovirus (1), influenza (2), rhinovirus (1), coccidiomycoses (1), adenovirus, Haemophilus influenza, Penicillium and Nocardia (the latter four organisms seen with one single RSV infectious episode). Infiltrates on radiological studies and increased effort to breathe were noted in all seven cases, with five of seven episodes and two of seven episodes requiring oxygen supplementation and mechanical ventilation, respectively. Five of seven LRTIs were diagnosed at a time when regularly scheduled IVIG was being administered to patients. All seven cases were treated with either increased frequency or additional doses of IVIG. Only one case (a 7-month-old patient) received palivizumab before and after diagnosis. RSV was confirmed negative for five of seven cases with a median of 33 days (range 1-218) between PCR-positive and -negative results. Six of seven cases resulted in a return to clinical baseline. The remaining case involved a patient with a rapid 2-week multiorgan system failure and death; autopsy confirmed disseminated coccidiomycosis.

Only a minority of HSCT recipients in our retrospective study cohort had an RSV infection presenting with or progressing to an LRTI. Viral LRTIs have been shown to be less common during the first 100 days post HSCT when a non-myeloablative regimen is used. $^{8}$ However, our patients with LRTI occurring in the first
100 days received reduced intensity conditioning regimens. HSCT patients who received cord or bone marrow stem cells have also been reported to have higher mortality risk because of RSV. ${ }^{9}$ However, all four patients who received cord blood stem cell transplants in our series presented with URTIs and recovered. Additionally, three of six patients with LRTIs in our cohort who received bone marrow stem cells as their transplant all completely recovered from their infections.

Additional HSCT-associated risk factors reported to contribute to RSV LRTI progression and death include infection early post transplant (before 100 days), neutropenia (ANC $<500$ cells per $\mathrm{mm}^{3}$ ), lymphocytopenia (absolute lymphocyte count $<200$ cells per $\mu \mathrm{L}$ ), young age ( $<2$ years), concomitant immunosuppression and bacterial coinfections. ${ }^{4,6,7}$ Four of $37(11 \%)$ patients presented with infection before neutrophil engraftment, but only one has an LRTI. Additionally, only one of nine infections occurring in patients with an ANC $<500$ presented as an LRTI. This suggests good outcomes despite infections early post HSCT and/or with concurrent severe neutropenia. In our cohort, young age was not a prominent risk factor. However, coinfections reached statistical significance. Eight of 30 (27\%) URTIs and six of seven $(86 \%)$ LRTIs were diagnosed in patients with documented coinfections. Comorbidities such as bronchiolitis obliterans also significantly impacted presentation and progression.

No treatment is considered standard of care for RSV infection post-HSCT. Shah et al. ${ }^{6}$ reported that inhaled ribavirin, when used alone or with IVIG and/or palivizumab, may prevent progression from URTI to LRTI and effect all-cause mortality. A meta-analysis examining the use of inhaled ribavirin plus IVIG with or without palivizumab showed a statistically significant impact on overall survival. ${ }^{7}$ Chemaly et al. $^{4}$ concluded that the low overall mortality $(3 / 19$ or $16 \%)$ observed in pediatric oncology patients with RSV-associated LRTIs was due directly to ribavirin use. However, the authors failed to show a statistically significant difference in reducing risk of progression from URTI to LRTI. ${ }^{4}$ In general, these reports are retrospective and not rigorously controlled clinical 
trials. Our patients received routine supplementation with IVIG every 1-2 weeks until normal levels for age were maintained. It is possible that passive immunity was provided to our patients with these infusions as analysis of IVIG lots show a uniform and consistent presence of antibodies against RSV. ${ }^{10}$ Our RSV-targeted therapy, when used, consisted of additional doses of IVIG to increase passive immunity with or without addition of palivizumab. Palivizumab was used in certain patients based on physician preference and current available guidelines. ${ }^{11,12}$ Previous studies that found little to no survival advantage in patients treated with palivizumab \pm IVIG restricted their analysis to patients who only received IVIG after the diagnosis of an RSV-associated infection was made. There is no indication these patients were receiving regularly scheduled IVIG post HSCT to maintain levels normal for age. ${ }^{7,9,13}$

There were no deaths attributed to RSV infection in our patients. Overall, only six (19\%) patients in our cohort progressed to LRTI. This is much lower than previous reports, where up to $50 \%$ of RSV-infected HSCT patients progressed to LRTI, resulting in mortality rates of $12-55 \% ., 14,15$ Our study is limited by being retrospective with a small number of patients. However, our findings differ from established literature and show presentation patterns and clinical outcomes that are better than previously reported. Of note, these outcomes occurred without the use of inhaled ribavirin, previously reported as improving overall survival.

\section{CONFLICT OF INTEREST}

The authors declare no conflict of interest.

J El-Bietar ${ }^{1}$, A Nelson ${ }^{1}$, G Wallace ${ }^{1}$, C Dandoy $^{1}$, S Jodele ${ }^{1}$, KC Myers ${ }^{1}$, A Teusink $^{1,2}$, A Lane ${ }^{1}$, SM Davies $^{1}$ and L Danziger-Isakov ${ }^{2}$

${ }^{1}$ Division of Bone Marrow Transplantation and Immune Deficiency, Cincinnati Children's Hospital Medical Center, Cincinnati, $\mathrm{OH}$, USA and

${ }^{2}$ Division of Infectious Diseases, Cincinnati Children's Hospital Medical Center, Cincinnati, OH, USA E-mail: javier.el-bietar@cchmc.org

\section{REFERENCES}

1 El Saleeby CM, Somes GW, DeVincenzo JP, Gaur AH. Risk factors for severe respiratory syncytial virus disease in children with cancer: the importance of lymphopenia and young age. Pediatrics 2008; 121: 235-243.
2 Erard V, Chien JW, Kim HW, Nichols WG, Flowers ME, Martin PJ et al. Airflow decline after myeloablative allogeneic hematopoietic cell transplantation: the role of community respiratory viruses. J Infect Dis 2006; 193: 1619-1625.

3 Boeckh M, Englund J, Li Y, Miller C, Cross A, Fernandez H et al. Randomized controlled multicenter trial of aerosolized ribavirin for respiratory syncytial virus upper respiratory tract infection in hematopoietic cell transplant recipients. Clin Infect Dis 2007; 44: 245-249.

4 Chemaly RF, Ghantoji SS, Shah DP, Shah JN, El Taoum KK, Champlin RE et al. Respiratory syncytial virus infections in children with cancer. J Pediatr Hematol Oncol 2014; 36: e376-381.

5 Chemaly RF, Torres HA, Munsell MF, Shah DP, Rathod DB, Bodey GP et al. An adaptive randomized trial of an intermittent dosing schedule of aerosolized ribavirin in patients with cancer and respiratory syncytial virus infection. $J$ Infect Dis 2012; 206: 1367-1371.

6 Shah DP, Ghantoji SS, Shah JN, El Taoum KK, Jiang Y, Popat U et al. Impact of aerosolized ribavirin on mortality in 280 allogeneic haematopoietic stem cell transplant recipients with respiratory syncytial virus infections. I Antimicrob Chemother 2013; 68: 1872-1880.

7 Shah JN, Chemaly RF. Management of RSV infections in adult recipients of hematopoietic stem cell transplantation. Blood 2011; 117: 2755-2763.

8 Schiffer JT, Kirby K, Sandmaier B, Storb R, Corey L, Boeckh M. Timing and severity of community acquired respiratory virus infections after myeloablative versus non-myeloablative hematopoietic stem cell transplantation. Haematologica 2009; 94: $1101-1108$

9 Seo S, Campbell AP, Xie H, Chien JW, Leisenring WM, Englund JA et al. Outcome of respiratory syncytial virus lower respiratory tract disease in hematopoietic cell transplant recipients receiving aerosolized ribavirin: significance of stem cell source and oxygen requirement. Biol Blood Marrow Transplant 2013; 19: 589-596.

10 Matejtschuk P, Chidwick K, Prince A, More JE, Goldblatt D. A direct comparison of the antigen-specific antibody profiles of intravenous immunoglobulins derived from US and UK donor plasma. Vox Sang 2002; 83: 17-22.

11 Committee on Infectious D. From the American Academy of Pediatrics: Policy statements-Modified recommendations for use of palivizumab for prevention of respiratory syncytial virus infections. Pediatrics 2009; 124: 1694-1701.

12 Kassis C, Champlin RE, Hachem RY, Hosing C, Tarrand JJ, Perego CA et al. Detection and control of a nosocomial respiratory syncytial virus outbreak in a stem cell transplantation unit: the role of palivizumab. Biol Blood Marrow Transplant 2010; 16: 1265-1271.

13 de Fontbrune FS, Robin M, Porcher R, Scieux C, de Latour RP, Ferry C et al. Palivizumab treatment of respiratory syncytial virus infection after allogeneic hematopoietic stem cell transplantation. Clin Infect Dis 2007; 45: 1019-1024.

14 Adams R, Christenson J, Petersen F, Beatty P. Pre-emptive use of aerosolized ribavirin in the treatment of asymptomatic pediatric marrow transplant patients testing positive for RSV. Bone Marrow Transplant 1999; 24: 661-664.

15 Chavez-Bueno S, Mejias A, Merryman RA, Ahmad N, Jafri HS, Ramilo O. Intravenous palivizumab and ribavirin combination for respiratory syncytial virus disease in high-risk pediatric patients. Pediatr Infect Dis J 2007; 26: 1089-1093. 